\title{
BMJ Open Prehospital time and mortality in patients requiring a highest priority emergency medical response: a Danish registry-based cohort study
}

\author{
Elisabeth Helen Anna Mills (D) , ${ }^{1}$ Kristian Aasbjerg, ${ }^{1}$ Steen Moeller Hansen, ${ }^{1}$ \\ Kristian Bundgaard Ringgren, ${ }^{1}$ Michael Dahl, ${ }^{2}$ Bodil Steen Rasmussen, ${ }^{2}$ \\ Christian Torp-Pedersen, ${ }^{3,4}$ Peter Søgaard, ${ }^{4}$ Kristian Kragholm ${ }^{2,5}$
}

To cite: Mills EHA, Aasbjerg K, Hansen SM, et al. Prehospital time and mortality in patients requiring a highest priority emergency medical response: a Danish registry-based cohort study. BMJ Open 2019;9:e023049. doi:10.1136/ bmjopen-2018-023049

- Prepublication history and additional material for this paper are available online. To view these files, please visit the journal online (http://dx.doi org/10.1136bmjopen-2018023049).

Received 05 April 2018 Revised 23 June 2019 Accepted 10 July 2019

Check for updates

(C) Author(s) (or their employer(s)) 2019. Re-use permitted under CC BY-NC. No commercial re-use. See rights and permissions. Published by BMJ.

For numbered affiliations see end of article.

Correspondence to

Dr Elisabeth Helen Anna Mills; e.mills@rn.dk

\section{ABSTRACT}

Objective To examine the association between time from emergency medical service vehicle dispatch to hospital arrival and 1-day and 30-day mortality.

Design Register-based cohort study.

Setting North Denmark Region $\left(\approx 8000 \mathrm{~km}^{2}\right.$, catchment population $\approx 600000$ ).

Participants We included all highest priority dispatched ambulance transports in North Denmark Region in 20062012.

Interventions Using logistic regression and the g-formula approach, we examined the association between time from emergency dispatch to hospital arrival and mortality for presumed heart, respiratory, cerebrovascular and other presumed medical conditions, as well as traffic or other accidents, as classified by emergency dispatch personnel. Main outcome measures 1-day and 30-day mortality. Results Among 93167 individuals with highest priority ambulances dispatched, 1948 (2.1\%) were dead before the ambulance arrived and 19968 (21.4\%) were transported to the hospital under highest priority (median total prehospital time from dispatch to hospital arrival $47 \mathrm{~min}$ (25\%-75\%: 35-60 min); 95th percentile $84 \mathrm{~min})$. Among 18709 with population data, 1-day mortality was $10.9 \%(n=2038)$, and was highest for patients with dyspnoea (20.4\%) and lowest for patients with traffic accidents (2.8\%). Thirty-day mortality was $18.3 \%$ and varied between $36.6 \%$ (patients with dyspnoea) and $3.7 \%$ (traffic accidents). One-day mortality was not associated with total prehospital time, except for presumed heart conditions, where longer prehospital time was associated with decreased mortality: adjusted $\mathrm{OR}$ for $>60 \mathrm{~min}$ vs 0-30 min was 0.61 (95\% Cl 0.40 to 0.91). For patients with dyspnoea, 0 R for $>60$ min vs $0-30$ min was 0.90 (95\% Cl 0.56 to 1.45), for presumed cerebrovascular conditions OR 1.41 (95\% Cl 0.53 to 3.78), for other presumed medical conditions $0 \mathrm{R} 0.84(95 \% \mathrm{Cl} 0.70$ to 1.02), for traffic accidents $0 \mathrm{R} 0.65$ (95\% Cl 0.29 to 1.48) and for other accidents OR 0.84 ( $95 \% \mathrm{Cl} 0.47$ to 1.51). Similar findings were found for 30-day mortality. Conclusions In this study, where time from emergency dispatch to hospital arrival mainly was $<80 \mathrm{~min}$, there was no overall relation between this prehospital time measure and mortality.
Strengths and limitations of this study

- Prehospital services registry data were available for all ambulance transports in the entire North Denmark Region between 2006 and 2012.

- Population data, including 30-day mortality, were available for most participants.

- The study is observational, meaning results are associations and not necessarily causal.

\section{INTRODUCTION}

Centralisation of emergency care is progressing in many European countries. ${ }^{2}$ Consequently, the average prehospital time for patients requiring emergency medical care increases due to increases in transport distance. ${ }^{1-3}$ This raises a concern that patient outcomes might be adversely affected by increases in prehospital time. Prior studies have found increased mortality with prolonged transport following acute myocardial infarction, unintentional injuries and respiratory emergencies. ${ }^{4-6}$ In contrast, centralisation of medical specialties could lead to better quality of care and ultimately better outcomes, thus justifying longer transport distance. ${ }^{2} 78$ A UK-based cluster randomised study of bypass of non-specialist hospitals in favour of specialist neuroscience centres did not find differences in the 30-day mortality of patients with suspected traumatic brain injury, where travelling time to the neuroscience centre was less than 1 hour. $^{9}$

There is insufficient knowledge about the impact of prehospital times on mortality. ${ }^{10} 11$ Guidelines exist for certain conditions where outcomes are known to be influenced by delays: for ST elevation myocardial infarction (STEMI), a first medical contact to device (coronary intervention) time of less than $90 \mathrm{~min}$ is recommended $^{12}$; and for acute 
ischaemic stroke, acute thrombolysis is recommended up to 4.5 hours after symptom onset. ${ }^{13}$ For trauma patients, guidelines recommend that total prehospital time should be kept below $60 \mathrm{~min}$ (the so-called 'golden hour') despite little supporting evidence ${ }^{14}{ }^{15}$; however, a Swiss study on blunt trauma found that patients with prehospital times above $60 \mathrm{~min}$ were more likely to have an on-scene emergency physician present, and these patients with longer prehospital times had decreased 30-day mortality. ${ }^{16}$

Given the insufficient knowledge on the impact of prehospital times on mortality for medical conditions other than STEMI and stroke, we examined data from the electronic prehospital emergency patient record (amPHI) database containing all emergency transports in the North Denmark Region between 2006 and 2012. We selected patients with highest priority ambulance dispatch and transport to hospital, driving with 'lights-and-sirens', meaning that ambulances may drive faster than the speed limit. We studied the influence of total prehospital time, defined as time from emergency dispatch to hospital arrival, on both 1-day and 30-day mortality in patients with presumed cardiac or respiratory conditions, presumed cerebrovascular conditions, other presumed medical conditions, traffic or other accidents.

\section{METHODS}

\section{Study setting}

This register-based study was conducted using prehospital registry data between 4 April 2006 and 1 December 2012 in the North Denmark Region. The North Denmark Region covers a population of approximately 600000 per 1 January 2012 in an area of approximately $8000 \mathrm{~km}^{2}$, consisting mainly of suburban (areas with 2500-50 000 citizens) and rural ( $<2500$ citizens) areas, and only one urban area (area with population $>50000$ ). ${ }^{17}$

In all regions of Denmark, prehospital emergency medical service (EMS) is tax-financed and free of charge for all citizens requiring emergency medical response. Prehospital emergency care is primarily at a basic life support level carried out by ambulance staff (an emergency medical technician (EMT) and an ambulance assistant); this ambulance staff also transports the patients to the hospital. In addition, rapid response units (RRUs) staffed with paramedics (advanced life support) or mobile emergency care units (MECUs) staffed with a prehospital emergency physician (an anaesthesiologist) and a paramedic are dispatched to assist EMT personnel when the emergency call seems critical. While military helicopters have transported patients over a number of years, a formalised air ambulance organisation with doctors was only established in the North Denmark Region in 2011, with a report mentioning 31 ambulance transports from 1 June to 31 December 2011. The helicopter is located to primarily service areas farthest away from major hospitals. ${ }^{18-20}$

To minimise EMS response time (defined as the time between ambulance dispatch to arrival of the first ambulance on the scene), ambulances are continuously moved to different locations in an attempt to meet contractual agreements of the average EMS response time of $9 \mathrm{~min}$ and $12 \mathrm{~s}$ in cases where medical conditions require the most urgent priority 1 response. ${ }^{21}$ The dispatch centre, staffed with logistic personnel until 2011 and with healthcare professionals (nurses) from 2011 and onwards, determines how acute the patient's condition is and may dispatch the ambulance as priority 1 through priority 5 , of which priority 1 is lights-and-sirens. When driving with lights-and-sirens, ambulances can drive faster than the speed limit. After arrival and treatment on the scene, the ambulance staff may choose to transport the patient to the hospital with the same priority level, change it or decide that the patient does not need to be transported to the hospital; the latter requires consultation with the prehospital emergency physician. There are several hospitals in the region handling the emergency care treatments, including one level 1 trauma centre also capable of providing tertiary care, such as percutaneous coronary intervention (PCI) and thoracic, vascular and neurosurgery, and two level 2 trauma centres without tertiary care. ${ }^{22}$ In the case of presumed cardiac conditions, patients with ambulance ECGs reflecting STEMI must be sent to tertiary centres capable of PCI, whereas other conditions (eg, unstable angina or non-ST segment elevation myocardial infarction) are sent to the nearest cardiological department. ${ }^{23}$

\section{Study population}

We initially identified all patients requiring dispatch of the most urgent priority 1 response to the scene. For patients with more than one ambulance transport during the study period, we chose the last dispatch to minimise underestimation of the influence of prehospital time on mortality. We excluded patients with missing total prehospital time. We reported prehospital mortality for all patients. Associations between total prehospital time and 1-day and 30-day mortality were estimated for patients who also had a priority 1 transport to the hospital and had population data. The study population selection is shown in figure 1.

\section{Patient and public involvement}

Patients were not involved in the design of this study.

\section{Data sources}

In Denmark, all citizens are assigned a permanent, unique civil registration number at birth. Hospitals are required by law to use the personal registration number as a reference to all hospital contacts. Also, this unique identifier is used in the amPHI database containing all emergency medical transports in the North Denmark Region since April 2006, enabling linkage between prehospital data and administrative registries.

From the amPHI database we included information on dates and times of (1) ambulance dispatch, (2) arrival of EMS ambulance personnel on the scene, (3) departure 


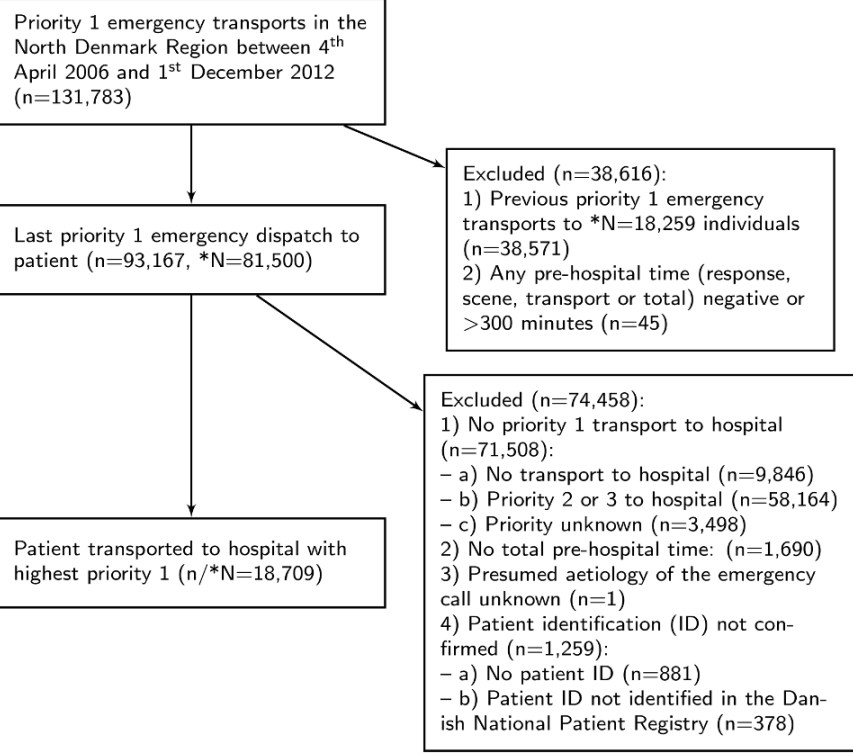

Figure 1 Flow chart showing patient selection from the amPHI database. * $\mathrm{N}$ refers to unique individuals with population data.

from the scene and (4) arrival at the hospital, allowing calculation of the EMS response time, on-scene time and transport time, as well as the sum of these times defined as the total prehospital time. Information on the priority level of ambulance dispatch to the scene and priority level on return to the hospital was assessed. We used the presumed aetiology of the patient's condition based on the telephone information given to the logistical dispatch staff or nurses at the dispatch central to categorise patients according to presumed cardiac and cerebrovascular conditions, dyspnoea, and other presumed medical conditions, traffic accidents (ie, involving motor vehicle collisions, cyclists or pedestrians) or other accidents, and unknown conditions. Patients who had a trauma score activating the in-hospital trauma team were reported across the conditions. Similarly, patients with a cardiac arrest, identified by cardiac rhythm (shockable or nonshockable rhythm), or respiration and circulation status on arrival to the scene (no or abnormal respiration and no circulation), or initiation of chest compressions or administration of a defibrillator shock, or use of intravenous epinephrine, were reported across the conditions. Prehospital airways procedures, medication and oxygen usage, and spine board and neck brace usage were also noted.

Data on whether MECUs or rapid response units were dispatched in parallel with the ambulance were included from the amPHI registry and similarly reported across the groups. Data on helicopter use were identified through postcodes consistent with helicopter departure and landing sites, and the corresponding ambulances to and from the departure and landing site, respectively. ${ }^{24}$

Information on patient sex and date of birth and date(s) of emigration was included through linkage to the Danish Civil Registration systems. ${ }^{25}$ Hospital diagnoses within 1 day after the ambulance transport were obtained through linkage to the Danish National Patient Registry, from which primary diagnoses coded according to the International Classification of Diseases, Tenth Revision (ICD-10) were obtained (alternatively, referral diagnoses when no primary diagnoses were identified). Each patient could have multiple diagnoses. For ICD-10 chapters I-VIII and X-XXI, one diagnosis within each chapter was noted. For ICD-10 chapter IX, the following specific conditions were noted: ischaemic heart disease, aortic aneurysm, cardiac arrest, heart failure, arrhythmia and cerebrovascular diseases. PCI and coronary artery bypass grafting $(\mathrm{CABG})$ procedures carried out within 30 days after ambulance transport were also noted (procedure codes for CABG: KFNA-KFNE; for PCI: KFNG).

\section{Main exposure}

The main exposure was total prehospital time defined as the time from ambulance dispatch to arrival at the hospital. We divided total prehospital time into preselected intervals of $0-30,>30-45,>45-60$ and $>60 \mathrm{~min}$. These time intervals were chosen based on current literature, ${ }^{11-1326}$ as well as to allow adequate sample size across the groups. Patients were stratified according to the presumed aetiology of the emergency call, including cardiac and cerebrovascular conditions, dyspnoea, and other presumed medical conditions, traffic or other accidents, and unknown conditions.

\section{Outcomes}

We assessed prehospital, 1-day and 30-day mortality. One-day and 30-day mortality outcomes were assessed by linking prehospital patient data to the Danish National Cause of Death Registry, but only possible for patients with a valid civil registration number. ${ }^{27}$

Prehospital mortality may have occurred prior to ambulance arrival or may occur within the transport interval for which the emergency services were responsible. The person was only declared dead in the field if there were obvious signs of death (ie, livores and/or rigor mortis) or the prehospital emergency physician was present according to the Danish legislation. Any instances of patients with ongoing resuscitative efforts or contacts where the emergency physician was not involved to declare a person dead at the time of hospital arrival were not regarded as prehospital mortality. However, when patients were declared dead in the field, they were included in the 1-day and 30-day mortality measures.

\section{Statistical analyses \\ Main analyses}

Categorical variables were summarised using frequencies and percentages, and continuous variables using medians and quartiles. The $\chi^{2}$ test was performed on categorical variables and the Kruskal-Wallis on continuous variables, using the $\mathrm{R}$ Publish package. ${ }^{28}$ Crude analyses and analyses adjusted for age, sex and comorbidity were performed to examine the relationship between total 
prehospital time and 1-day and 30-day mortality, using logistic regression. These analyses were performed separately for each of the presumed emergency conditions (heart conditions, cerebrovascular conditions, dyspnoea, other presumed medical conditions, traffic or other accidents) and presented on the same figure.

The association between total prehospital time and mortality was further modelled by the g-formula analysis. The g-formula approach analyses an observational (non-randomised) study which, under assumptions of consistency, exchangeability (given measured covariates), positivity and a well-defined exposure, may mimic a randomised controlled trial. ${ }^{29}$ Our data contain the actual observed mortality outcome, given the total prehospital time each patient had in reality been exposed to; in contrast, the concept of potential outcomes (counterfactuals) is the patient's outcome if they had been exposed to a different prehospital time, even though we can only ever observe the outcome under one particular exposure. ${ }^{30}$ Within each presumed condition, we exposed each individual with their own covariates (age, sex, Charlson Comorbidity Index score) to all different total prehospital time intervals ( $15 \mathrm{~min}$ intervals), thus generating for each individual a set of potential outcomes, one for each total prehospital time interval. These potential outcomes were predictions obtained from multiple logistic regression models, adjusted for age, sex and comorbidities. We reported marginal differences (ie, average causal effects) ${ }^{30-33}$ of mortality for $15 \mathrm{~min}$ time intervals for each disease group with pointwise bootstrap 95\% CIs and presented these graphically.

\section{Additional analyses}

- Adjusted logistic regression was also performed for the association between the total time and mortality for each patient's first ambulance transport in the time period; that is, for patients with more than one transport in the time period, the first transport was checked for inclusion (rather than their last transport as in the main analysis), whereas for patients with only one transport this transport was both the first and the last and thus included in both the main and additional analyses. The g-formula methods were also used to model the association between 30-day mortality for each patient's first ambulance transport in the time period.

- Logistic regression was also used to analyse the unadjusted association between EMS response time and 1-day and 30-day mortality in all individuals to whom a priority 1 ambulance had been dispatched, irrespective of return transport priority (priority 1,2 , other or none), with analyses stratified by the presumed emergency condition (heart and cerebrovascular conditions, dyspnoea, and other presumed medical conditions, traffic or other accidents, and unknown conditions).

- In addition, logistic regression was used to analyse the adjusted association between total prehospital time and 1-day and 30-day mortality for individuals transported to a non-tertiary and individuals transported to a tertiary centre. The g-formula methods were also used to model the association between total prehospital time and mortality for patients transported to a tertiary hospital or to a non-tertiary hospital.

Categorical and continuous variables were also presented for all patients: (1) to whom a priority 1 ambulance had been dispatched, divided by presumed conditions; (2) divided into those transported to hospital by priority 1 and those not; (3) all patients with priority 1 ambulance transport, divided by having a recorded total prehospital time or not; (4) patients with priority 1 ambulance transport, depending on the type of hospital (tertiary/non-tertiary) they were transported to; (5) prehospital times, prehospital procedures and medications were presented divided by the presence or absence of MECUs and rapid response units for all patients with priority 1 return and population data; and (6) ICD-10 diagnosis codes were presented divided by presumed conditions.

Data management was performed using SAS V.9.4. Statistical analyses were performed using $\mathrm{R}^{34}$

\section{RESULTS}

\section{Patients}

Figure 1 shows the flow chart of patient selection. We identified 93167 patients with 131783 emergency transports with the most urgent priority 1 emergency dispatch to the scene in the North Denmark Region between 4 April 2006 and 1 December 2012. For analysis, we included the latest emergency transport, leaving one emergency transport per patient. Of 93167 patients, 2.1\% (n=1948) died in the prehospital setting (online supplementary eTable 1). Patients with no priority 1 transport to the hospital were excluded (either no transport to the hospital, or priority 2 or 3 ); the included and excluded groups are compared in online supplementary eTable 2. Patients with missing total prehospital time were excluded; data for these patients are presented in online supplementary eTable 3. This left 19968 patients (21.4\%) who were also transported from the scene to the hospital with priority 1, with possibility for unadjusted analyses; 18709 patients with population data formed the study population for adjusted analyses (figure 1 ).

\section{Characteristics}

In table 1, patient, emergency dispatch and destination hospital characteristics as well as outcomes are shown for the 19968 patients with priority 1 response to the scene and priority 1 transport to the hospital stratified by the presumed emergency medical conditions (cardiac and cerebrovascular conditions, dyspnoea, and other medical conditions, as well as traffic or other accidents). Relative to all 93167 patients with priority 1 response to the scene, patients who also were transported from the scene to the hospital with priority 1 were more likely to have rapid 


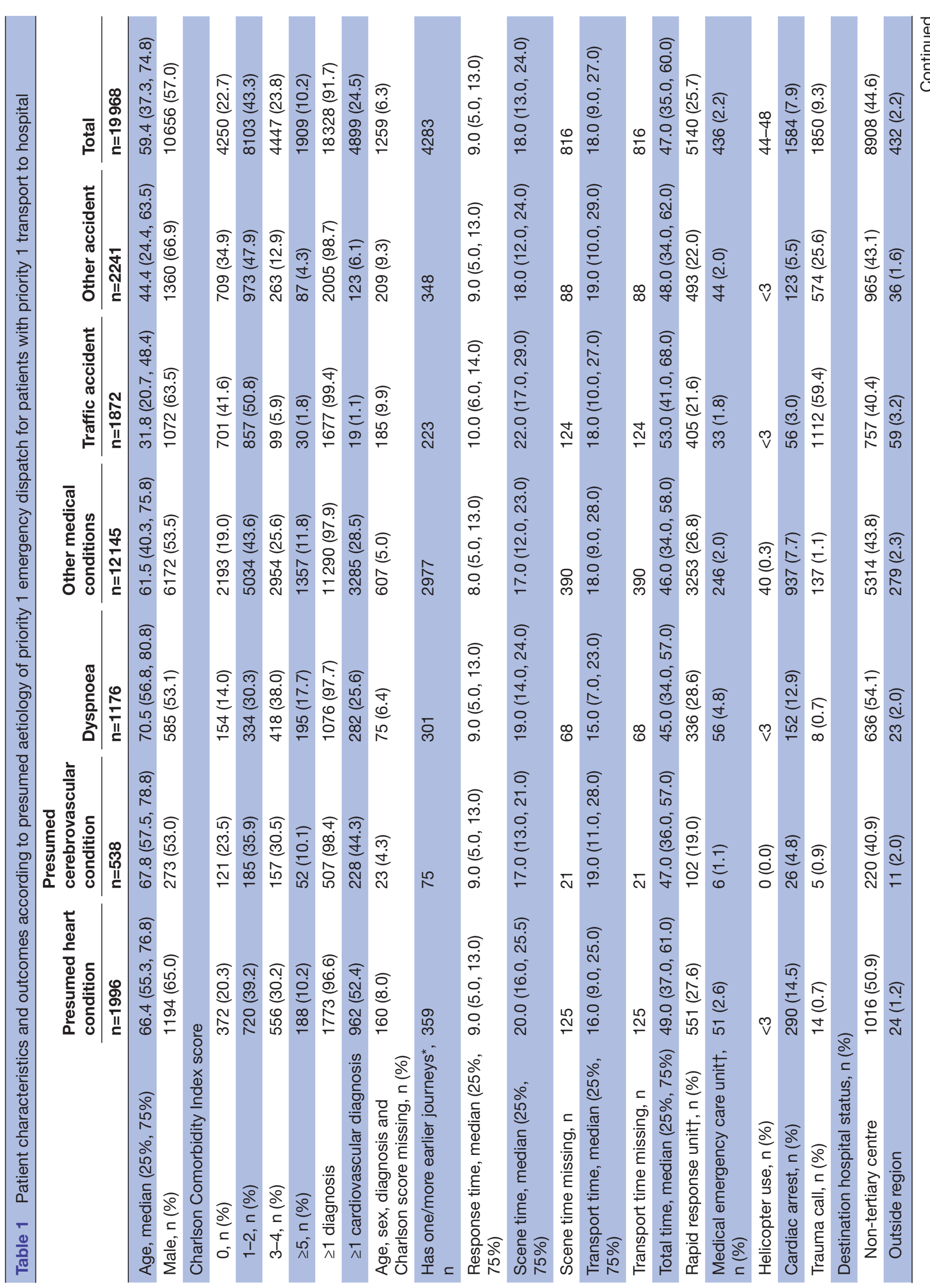




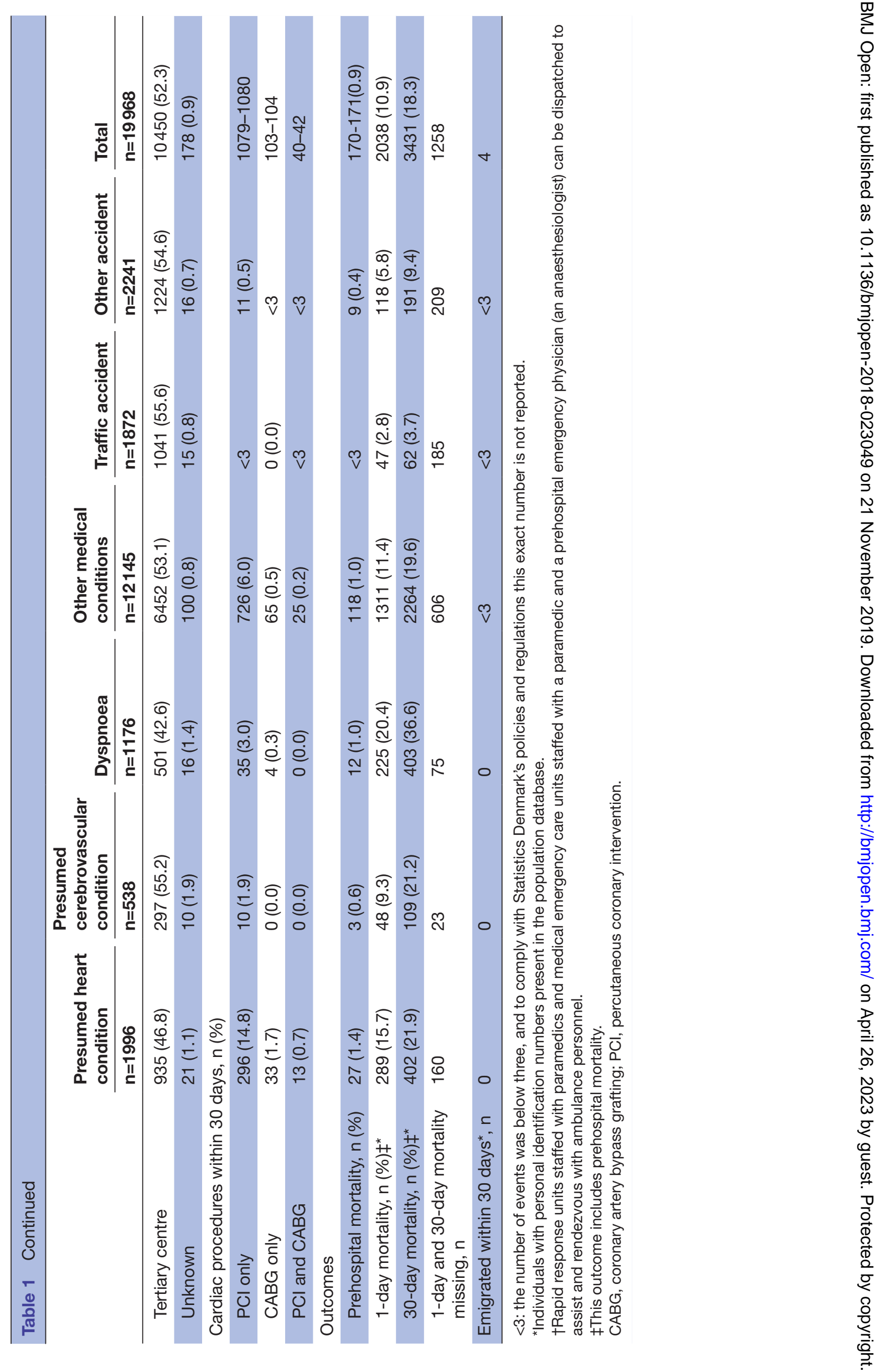


response units dispatched to the scene $(25.7 \%$ vs $19.2 \%$, $\mathrm{p}<0.0001)$, more likely to have cardiac arrest $(7.9 \%$ vs $4.2 \%, \mathrm{p}<0.0001)$, have the in-hospital trauma team activated $(9.3 \%$ vs $0.5 \%, \mathrm{p}<0.0001)$ and more likely to be transported to a tertiary hospital (table 1, online supplementary eTables 1 and 2).

No substantial differences were seen in EMS response time, on-scene time, transport time and ultimately total prehospital time across the conditions shown in table 1. Overall, the total prehospital time was mainly below $80 \mathrm{~min}$ (median $47 \mathrm{~min}, 25 \%-75 \%$ : 35-60 min; $95 \%$ percentile $84 \mathrm{~min}$ ). The overall median response time was below $9 \mathrm{~min}$ (25\%-75\%: 5-13 $\mathrm{min}$; $95 \%$ percentile $20 \mathrm{~min})$.

Overall, 6.3\% of patients had no population data, highest among traffic or other accidents $(9.9 \%$ and $9.3 \%$, respectively) and lowest among presumed cerebrovascular conditions $(4.3 \%) \quad(\mathrm{p}<0.0001)$. We were able to account for all patients at day 30 except for four patients who emigrated from Denmark during that period. These four patients were assumed to be alive at day 30. Patients involved in a traffic or other accident tended to be younger, have a lower Charlson Comorbidity Index score and were more likely of male sex. Compared with the two accident groups, patients with presumed heart and cerebrovascular conditions, dyspnoea and other medical conditions were older and had a more equal male to female distribution, apart from patients with presumed heart conditions who were more likely of male sex. Relative to patients with presumed heart conditions and dyspnoea, patients with presumed cerebrovascular conditions and other medical conditions and those involved in traffic or other accidents were more likely to be transported to a tertiary hospital centre (table 1).

The characteristics of patients with (19968) and without (1690) information on total prehospital time were comparable in relation to age, sex, comorbidities and EMS response time (online supplementary eTable 3 ). There were a higher proportion of patients with cardiac arrest, longer on-scene times and higher prehospital mortality among those without information on total time. The distribution of missingness across the presumed conditions was comparable. Online supplementary eTable 4 shows the characteristics of 19968 patients (priority 1 ambulance transports) divided by the receiving hospital type. Patients transported to non-tertiary centres were younger than those transported to tertiary centres. There were more cardiac arrests among patients transported to non-tertiary centres, whereas there were more cardiac procedures carried out among patients transported to a tertiary centre. Online supplementary eTable 5 shows prehospital times, prehospital procedures and medication usage according to the EMS level of care on the scene (ambulance only, rapid response units staffed by paramedics and mobile emergency car units (MECUs) staffed by a paramedic and an emergency physician). The median scene time was longer among rapid response units (median $22 \mathrm{~min}$, IQR 16-27) and MECUs (median
$21 \mathrm{~min}$, IQR 16-26min) than ambulance-only cases (median $17 \mathrm{~min}$, IQR $12-22 \mathrm{~min} \quad(\mathrm{p}<0.0001)$. Of the ambulance-only patients, $21.2 \%$ received no oxygen treatment, whereas $16.7 \%$ of those with RRUs and $18.0 \%$ of those with MECUs did. Oxygen masks were used by $66.4 \%$ of ambulance-only, $73.8 \%$ of RRU and $76.6 \%$ of MECU patients. Ventilation of patients was highest in RRU and MECU patients (14.9\% and $14.6 \%$ ), and lowest in ambulance-only patients (8.0\%). Online supplementary eTable 6 shows the associated primary or referral diagnoses of the patients. Nearly all 18709 patients had a hospital diagnosis beginning on the day or the day after patient transport. A total of $962(52.4 \%)$ patients with a presumed heart condition received at least one ICD-10 chapter IX diagnosis, most commonly a ischaemic condition (DI20-DI25, 518 patients, 28.2\%). Among patients with a presumed cerebrovascular condition, 186 (38.6\%) received a cerebrovascular diagnosis (DI60-DI69), and $39.1 \%$ of patients with dyspnoea received a chapter $\mathrm{X}$ respiratory diagnosis.

\section{Outcomes}

Prehospital, 1-day and 30-day mortality rates according to the presumed conditions are shown in table 1 for the 19968 patients with a priority 1 dispatch and subsequent priority 1 transport to the hospital (and in online supplementary eTable 1 for all 93167 patients with priority 1 dispatch to the scene). Prehospital mortality was lowest in traffic accidents and highest in patients with presumed heart conditions. Overall 1-day mortality was $10.9 \%$, and varied from $2.8 \%$ in patients involved in traffic accidents to $20.4 \%$ in patients with dyspnoea. Thirty-day mortality was $18.3 \%$, and varied between $3.7 \%$ in patients involved in traffic accidents and $36.6 \%$ in patients with dyspnoea (table 1). One-day and 30-day mortality rates were higher among patients with RRUs and MECUs on the scene (30day mortality $23.0 \%$ and $22.1 \%$ ) vs $16.6 \%$ for patients treated by ambulance personnel only (online supplementary eTable 5).

\section{Logistic regression, association between total prehospital time and mortality}

Figure 2 shows the relationship between total prehospital time and 1-day mortality by presumed condition for the 18709 patients who had a priority 1 response to the scene, as well as from the scene to the hospital, adjusted for patient age, sex and Charlson Comorbidity Index score. No significant associations between total prehospital time and 1-day mortality were found, except for patients with heart conditions for whom longer prehospital times were associated with lower mortality. Results were consistent with crude OR for the 18709 patients with population data (online supplementary eFigure 1). Figure 3 shows the patient age, sex and Charlson Comorbidity Index score adjusted association between total prehospital time and 30-day mortality for the same 18709 with a priority 1 transport to the hospital. Similar to the results for 1-day mortality, no significant association between total 


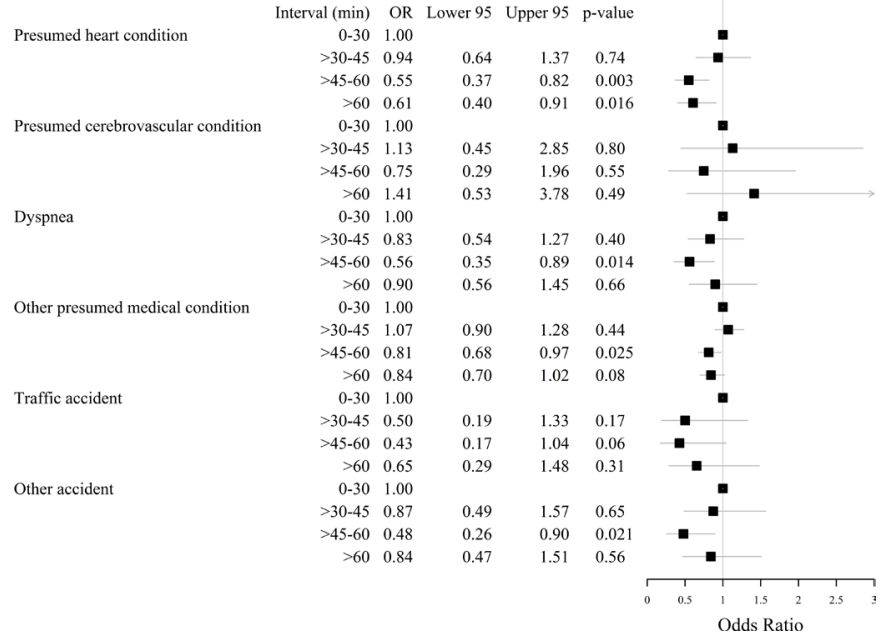

Figure 2 Age, sex and Charlson Comorbidity Index score adjusted OR of the associations between total prehospital time (from emergency dispatch to hospital arrival) and 1day mortality (including prehospital mortality) for patients with a presumed heart condition, cerebrovascular condition, dyspnoea, or other presumed medical conditions, or traffic or other accidents. $\mathrm{N}=18709$ patients with highest priority emergency response and highest priority transport to the hospital are included in the analysis, divided by group as follows: presumed heart condition 1836; cerebrovascular condition 515; dyspnoea 1101; other presumed medical conditions 11 538; traffic accidents 1687 ; and other accidents 2032 .

$\begin{array}{lrcccc} & \text { Interval ( }(\mathrm{min}) & \text { OR } & \text { Lower 95 } & \text { Upper 95 } & \text { p-value } \\ & 0-30 & 1.00 & & & \\ \text { Presumed heart condition } & >30-45 & 0.73 & 0.52 & 1.02 & 0.06 \\ & >45-60 & 0.44 & 0.31 & 0.63 & <0.001 \\ & >60 & 0.49 & 0.34 & 0.70 & <0.001 \\ & 0-30 & 1.00 & & & \\ \text { Presumed cercbrovascular condition } & >30-45 & 1.13 & 0.56 & 2.26 & 0.74 \\ & >45-60 & 0.85 & 0.42 & 1.71 & 0.66 \\ & >60 & 0.93 & 0.43 & 2.02 & 0.86 \\ \text { Dyspnea } & 0-30 & 1.00 & & & \\ & >30-45 & 0.86 & 0.58 & 1.27 & 0.45 \\ & >45-60 & 0.78 & 0.52 & 1.16 & 0.22 \\ \text { Other presumed medical condition } & >60 & 0.83 & 0.54 & 1.29 & 0.42 \\ & 0-30 & 1.00 & & & \\ & >30-45 & 1.04 & 0.90 & 1.21 & 0.57 \\ & >45-60 & 0.83 & 0.72 & 0.97 & 0.020 \\ \text { Traffic accident } & >60 & 0.85 & 0.72 & 0.99 & 0.042 \\ & 0-30 & 1.00 & & & \\ & >30-45 & 0.63 & 0.26 & 1.56 & 0.32 \\ & >45-60 & 0.60 & 0.27 & 1.35 & 0.22 \\ \text { Other accident } & >60 & 0.81 & 0.37 & 1.75 & 0.59 \\ & 0-30 & 1.00 & & & \\ & >30-45 & 1.06 & 0.62 & 1.81 & 0.82 \\ & >45-60 & 0.75 & 0.44 & 1.29 & 0.30 \\ & >60 & 1.04 & 0.61 & 1.77 & 0.88\end{array}$

Figure 3 Age, sex and Charlson Comorbidity Index score adjusted OR of the associations between total prehospital time (from emergency dispatch to hospital arrival) and 30day mortality (including prehospital and 1-day mortality) for patients with a presumed heart condition, cerebrovascular condition, dyspnoea, or other presumed medical conditions, or traffic or other accidents. $\mathrm{N}=18709$ patients with highest priority emergency response and highest priority transport to the hospital are included in the analysis, divided by group as follows: presumed heart condition 1836; cerebrovascular condition 515; dyspnoea 1101; other presumed medical conditions 11 538; traffic accidents 1687; and other accidents 2032.

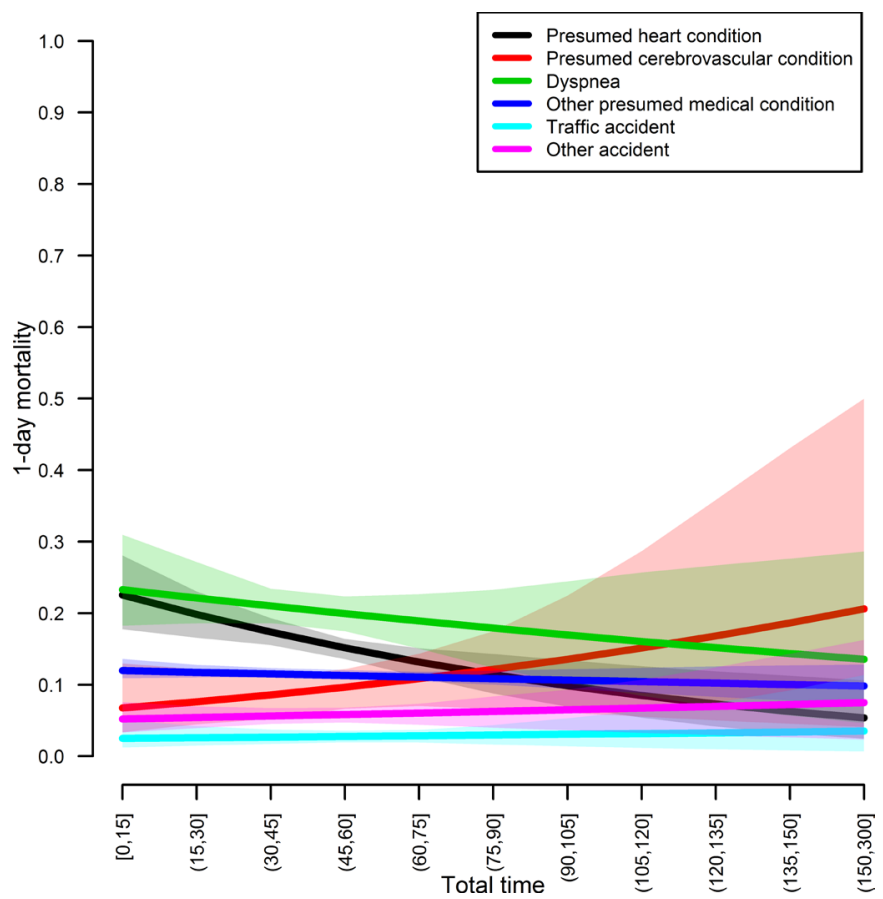

Figure 4 The g-formula analysis showing the relationship between total prehospital time (from emergency dispatch to hospital arrival) and 1-day mortality (including prehospital mortality) for patients with a presumed heart condition, presumed cerebrovascular condition, dyspnoea, or other presumed medical conditions, or traffic or other accidents. Analysis was adjusted for age, sex and Charlson Comorbidity Index score. All patients (within each presumed condition) were exposed to all total prehospital time intervals, with 95\% bootstrap Cls. $\mathrm{N}=18709$ patients with highest priority emergency transport to the scene and from the scene to the hospital are included in the analysis, divided by group as follows: presumed heart condition 1836; cerebrovascular condition 515; dyspnoea 1101; other presumed medical conditions 11 538; traffic accidents 1687; and other accidents 2032 .

prehospital time and 30-day mortality was seen, except for presumed cardiac conditions, where the odds declined with longer prehospital time (figure 3). These findings were consistent with crude OR for the 18709 patients with population data (online supplementary eFigure 2).

\section{The g-methods: total prehospital time and mortality}

These results were consistent in the adjusted g-formula analyses when simulating that within each presumed condition, patients were exposed to all prehospital time intervals. For both 1-day mortality (figure 4) and 30-day mortality (figure 5), mortality appeared to decrease with longer total prehospital times for presumed cardiac conditions.

\section{Additional analysis}

Of the patients, 4283 with population data had an earlier ambulance transport (table 1); in the analysis of each patient's first ambulance transport (which may have been the same as the last journey) (online supplementary eFigures 3 and 4), there was again lower OR of mortality for 


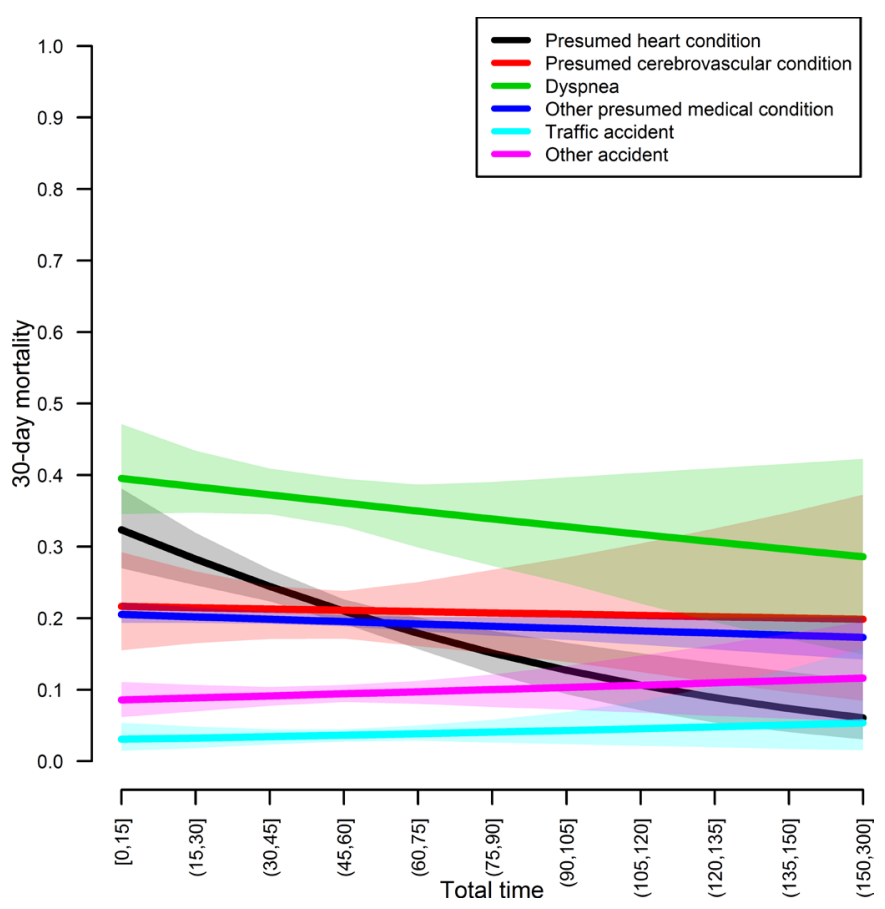

Figure 5 The g-formula analysis showing the relationship between total prehospital time (from emergency dispatch to hospital arrival) and 30-day mortality (including prehospital and 1-day mortality) for patients with a presumed heart condition, presumed cerebrovascular condition, dyspnoea, or other presumed medical conditions, or traffic or other accidents. Analysis was adjusted for age, sex and Charlson Comorbidity Index score. All patients (within each presumed condition) were exposed to all total prehospital time intervals, with $95 \%$ bootstrap Cls. $\mathrm{N}=18709$ patients with highest priority emergency transport to the scene and from the scene to the hospital are included in the analysis, divided by group as follows: presumed heart condition 1836; cerebrovascular condition 515; dyspnoea 1101; other presumed medical conditions 11 538; traffic accidents 1687; and other accidents 2032 .

longer transport times for presumed heart conditions, for both 1-day and 30-day mortality, as in figures 2 and 3. The 30-day mortality was lower in online supplementary eFigure 5 (first ambulance transport), compared with figure 5 (last ambulance transport). For 81571 patients with population data and dispatch of a priority 1 ambulance, the association between EMS response time intervals and 1-day mortality was insignificant across all patient conditions, except for patients who had experienced an 'other accident', where higher mortality odds was seen with longer response times (online supplementary eFigure 6). For 30-day mortality, lower mortality was seen with longer response times for dyspnoea: crude OR for $10-15 \mathrm{~min}$ vs $0-5 \mathrm{~min}$ was 0.76 (95\% CI 0.62 to 0.94 ) (online supplementary eFigure 7). Online supplementary eTable 4 compares patient characteristics depending on the type of receiving hospital. The percentages of presumed conditions were the same for tertiary and nontertiary hospitals, and total times were similar. Patients transported to a non-tertiary hospital were older and with more comorbidities. A higher percentage of patients transported to tertiary hospitals had PCIs and CABGs performed, and more MECUs were dispatched. Online supplementary eFigures 8 and 9 show the adjusted relationship between total prehospital time and 1-day and 30-day mortality for 8256 patients, with population data, transported to a non-tertiary hospital with the highest priority; these show significantly lower OR of mortality with longer times for presumed heart conditions, consistent with the results in figures 2 and 3. Online supplementary eFigures 10 and 11 show the relationship between total prehospital time and 1-day and 30-day mortality for 9896 patients (with population data) transported to a tertiary hospital, with no association between time intervals and OR of mortality across all presumed conditions. The g-methods analysis for total prehospital time and 30-day mortality found for non-tertiary hospitals (online supplementary eFigure 12) higher mortality for presumed heart conditions initially, dropping with longer total times, whereas for tertiary hospitals (online supplementary eFigure 13) the mortality was the same across all times.

\section{DISCUSSION}

The main result of this study was that 1-day and 30-day mortality outcomes were not associated with time from emergency dispatch to hospital arrival in patients requiring the most urgent response to the scene, as well as urgent transport from the scene to the hospital, where most time intervals from emergency dispatch to hospital arrival were below $80 \mathrm{~min}$. This finding did not vary across presumed medical conditions and accidents in neither crude nor adjusted analyses for sex, age and Charlson Comorbidity Index score groups, except for presumed heart conditions where both 1-day and 30-day mortality decreased with prolonged prehospital time. For traffic accidents 1-day (but not 30-day) mortality decreased with prolonged prehospital time in crude analyses, but this association was insignificant in adjusted analyses. In sensitivity analyses exploring associations between EMS response times and mortality among all patients with a priority 1 dispatch (irrespective of the transport priority to the hospital), no association was found between response intervals and mortality across all patient conditions, except for patients with dyspnoea where odds of mortality was lower with longer EMS response times. Our findings were generally consistent when limiting our analyses to patients transported to a non-tertiary hospital, who were less likely to have bypassed a local hospital to reach a more specialised hospital. For these patients transported to a non-tertiary hospital there was a lower mortality with longer total prehospital times for presumed heart conditions, as was also seen in the main results. The only difference between these supplementary analyses and the main results was that patients with other presumed medical conditions (other than dyspnoea, heart or cerebrovascular conditions) now also were associated with lower 
odds of mortality with longer prehospital time, as it was the case for patients with presumed heart conditions.

Our main finding of no influence of prehospital time on mortality is in agreement with some studies but in disagreement with others. Newgard $e t a p^{35}$ examined 3656 trauma patients, of whom $806(22.0 \%)$ died. The focus of this and a subsequent study was to evaluate 'the golden hour', but these studies could not detect a relation between prehospital time and mortality. ${ }^{2635}$ Buchmueller et $a l^{4}$ examined the importance of prehospital time indirectly by studying the relation between centralisation of hospitals and mortality. This study indicated that shutting down smaller hospitals with subsequent longer prehospital times were associated with increased mortality for a number of medical conditions. In a review of 20 studies of trauma patients, Harmsen $e a^{11}$ overall found a positive relation between shorter prehospital time and reduced mortality. Harmsen et al $l^{11}$ further found that longer specialised on-scene treatment reduced mortality.

While research and systematic reviews on the impact of total prehospital time on mortality exist for trauma patients, ${ }^{162635}$ knowledge about this is scarce for emergency medical conditions other than myocardial infarction. ${ }^{36-38}$ Research has been conducted in both urban settings ${ }^{39-41}$ and in mixed urban/rural settings. ${ }^{10} 3537$ However, usage of in-hospital mortality as outcome may underestimate mortality; therefore, it has been recommended that 30-day mortality instead should be used as outcome measure. ${ }^{11}$

For an interpretation of the varying results, the quality of prehospital care is important. In Denmark, ambulance personnel is educated in emergency treatment of patients, including basic life support, and further service with an anaesthesiologist can be dispatched when necessary. Furthermore, a paramedic educated in administering certain drugs can be dispatched when necessary. In accordance with the findings of Harmsen et al, ${ }^{11}$ good quality prehospital care, with time spent on on-scene stabilisation and care, may minimise the benefits of short prehospital transportation time in favour of longer prehospital time intervals. An interpretation of the decreased mortality with longer transport for cardiac patients that we found in our study may likely reflect adequate prehospital triage of cardiac patients, including that an ECG is sent to a tertiary centre hospital for evaluation, with subsequent triage to a PCI-capable facility along with prehospital initiation of platelet-inhibiting drugs and preactivation of the catheterisation laboratory in the presence of STEMI. That relevant patients are redirected to a tertiary centre with PCI capability is likely to increase transportation time. Adequate prehospital treatments including plateletinhibiting drugs as well as bypass directly to a catheterisation laboratory instead of being taken to a closer non-PCI hospital are also likely to reduce mortality. ${ }^{42}$

The implication of this study is that longer prehospital times up to $80 \mathrm{~min}$ do not appear to be associated with increased mortality, in a setting where logistical dispatch staff and later nurses established the transport priority and where the prehospital treatment is provided by EMS personnel educated in basic life support emergency treatment, with the possibility of dispatching both paramedics trained in advanced life support as well as a trained prehospital emergency physician. The subject has important political implications, and prolonged transport time is a frequently cited argument for maintaining small community hospitals. It is important that this discussion is based on knowledge about the risk of prolonged transport time.

This study is not without limitations. The main limitation of this study is its observational nature, meaning that any significant findings are merely associations and not causal. However, our main finding was that the prehospital time did not appear to impact mortality up to $80 \mathrm{~min}$ between ambulance dispatch and hospital arrival. The g-formula statistics were applied to analyse this observational (non-randomised) study so that it mimics some of the particular characteristics of a randomised controlled trial. Based on the principle of interchangeability, the marginal differences were computed based on multiple logistic regressions assuming that the entire population within each presumed condition had a particular time interval. Our findings were consistent when using these methods. Second, we were only able to report 1-day and 30-day mortality outcomes for patients who were identified with a social security number. Prehospital mortality was recorded by ambulance personnel, when clear signs of death were present and/or a prehospital emergency physician was involved to declare a person dead in field, in accordance with Danish legislation. Use of 1-day mortality does not allow proper distinction between prehospital and in-hospital death, as 1-day mortality also captures deaths during the first day of admission. Third, the presumed conditions we used to classify the patients were based on assumptions made by emergency dispatch personnel and are not validated, but resemble hospital diagnoses. However, we found that patients with dyspnoea were those with the highest mortality rates, in agreement with other recent study findings. ${ }^{43}$ While emergency dispatch personnel establishes the presumed aetiology and subsequently determines the priority of the transport, EMS personnel including paramedics and emergency physicians, when dispatched, establish the priority of the transport from the scene to the hospital. Finally, the vast majority of patients $(95 \%)$ had a total prehospital time of $\leq 84 \mathrm{~min}$, and the EMS consisted of several levels of care, from ambulance personnel to paramedics and MECUs with a paramedic and an emergency physician, which may affect the generalisability and applicability of our study findings. A number of patients had missing data on total time (online supplementary eTable 3). Differences between patients with and without this time variable were small in relation to age, sex, comorbidities and EMS response time, except for dyspnoea (online supplementary eFigures 6 and 7). Status on arrival by the patient indicated a higher proportion of patients with cardiac arrest, longer on-scene times and higher 
prehospital mortality among those without a total time, indicating that these patients may represent cases where death was inevitable. However, the distribution of missingness across the presumed conditions was comparable. Importantly, among those transported to the hospital with data on total prehospital time, no overall differences in mortality were apparent across the presumed conditions, indicating that prehospital time for transportable patients is of no importance for mortality outcome. Our findings should be interpreted with this information in mind.

In conclusion, neither 1-day nor 30-day mortality seems to depend on time from emergency dispatch to hospital arrival, where most of these prehospital times were below $80 \mathrm{~min}$. This finding did not vary across selected symptom and disease categories, except for presumed cardiac conditions where 1-day and 30-day mortality decreased with prolonged total prehospital time.

\section{Author affiliations}

${ }^{1}$ Department of Epidemiology and Biostatistics, Aalborg University Hospital, Aalborg, Denmark

${ }^{2}$ Department of Anaesthesiology and Intensive Care Medicine, Aalborg University Hospital, Aalborg, Denmark

${ }^{3}$ Department of Cardiology and Clinical Research, Nordsjællands Hospital, Hillerød, Denmark

${ }^{4}$ Department of Cardiology, Aalborg University Hospital, Aalborg, Denmark ${ }^{5}$ Department of Cardiology and Epidemiology/Biostatistics, Aalborg University Hospital, Aalborg, Denmark

Acknowledgements The authors wish to thank John Gade from Judex A/S for his help with answering questions regarding data definitions and variables concerning the amPHI database.

Contributors All nine authors have contributed to the manuscript. EHAM, KA, CT-P and KK have drafted the idea. EHAM and KK had full access to the data. EHAM, KA, SMH, KBR, CT-P and KK all contributed to the data analysis. MD, BSR and PS provided clinical insight. EHAM prepared the first draft of the paper. All authors have participated in the revision of the manuscript.

Funding The study was supported by the Danish Heart Foundation and the Program for Clinical Research Infrastructure (PROCRIN) established by the Lundbeck Foundation and the Novo Nordisk Foundation. The Danish Heart Foundation and PROCRIN were not involved in the analysis nor in the interpretation of the study.

Competing interests SMH is supported by the Danish foundation TrygFonden. CT-P has received grants from Bayer and Biotronic and has received speaker honorarium from Bayer. PS reports research grants and personal fees from Biotronik, personal fees from Novartis, personal fees from AstraZeneca, research grants from GE Healthcare and research grants from EBR Systems. KK has received grants from the Laerdal Foundation and has received speaker's honoraria from Novartis.

\section{Patient consent for publication Not required.}

Ethics approval Registry-based studies do not require ethical approval in Denmark. Data access and analysis were approved by the Danish Data Protection Agency (reference 2007-58-0015, GEH-2014-019, I-suite 02737).

Provenance and peer review Not commissioned; externally peer reviewed.

Data availability statement Data may be obtained from a third party and are not publicly available.

Open access This is an open access article distributed in accordance with the Creative Commons Attribution Non Commercial (CC BY-NC 4.0) license, which permits others to distribute, remix, adapt, build upon this work non-commercially, and license their derivative works on different terms, provided the original work is properly cited, appropriate credit is given, any changes made indicated, and the use is non-commercial. See: http://creativecommons.org/licenses/by-nc/4.0/.
ORCID iD

Elisabeth Helen Anna Mills http://orcid.org/0000-0002-7499-3880

\section{REFERENCES}

1. HOPE Publications. Hospitals in Europe: healthcare data. Brussels, 2014. Available: http://www.hope.be/03activities/quality_euhospitals/eu_country_profiles/00-hospitals_in_europe-synthesis.pdf

2. Christiansen T. Ten years of structural reforms in Danish healthcare. Health Policy 2012;106:114-9.

3. Hansen BH, Toft LV. Kortlægning af afstand til nærmeste sygehus med akutmodtagelse - Før og efter implementering af den nye sygehusstruktur. Copenhagen, 2015. Available: http://www.kl.dk/ ImageVaultFiles/id_73248/cf_202/Kortl-gning_af_afstand_til_nrmeste_supersygehus.PDF [Äccessed 14 Aug 2015].

4. Buchmueller TC, Jacobson M, Wold C. How far to the hospital? The effect of hospital closures on access to care. J Health Econ 2006;25:740-61.

5. Nicholl J, West J, Goodacre S, et al. The relationship between distance to hospital and patient mortality in emergencies: an observational study. Emerg Med J 2007;24:665-8.

6. Shen Y-C, Hsia RY. Does decreased access to emergency departments affect patient outcomes? analysis of acute myocardial infarction population 1996-2005. Health Serv Res 2012;47:188-210.

7. Cha WC, Lee SC, Shin SD, et al. Regionalisation of out-of-hospital cardiac arrest care for patients without prehospital return of spontaneous circulation. Resuscitation 2012;83:1338-42.

8. Minei JP, Fabian TC, Guffey DM, et al. Increased trauma center volume is associated with improved survival after severe injury: results of a resuscitation outcomes Consortium study. Ann Surg 2014;260:456-64.

9. Lecky F, Russell W, Fuller G, et al. The head injury transportation straight to neurosurgery (HITS-NS) randomised trial: a feasibility study. Health Technol Assess 2016;20:1-198.

10. Weiss S, Fullerton L, Oglesbee S, et al. Does ambulance response time influence patient condition among patients with specific medical and trauma emergencies? South Med J 2013;106:230-5.

11. Harmsen AMK, Giannakopoulos GF, Moerbeek PR, et al. The influence of prehospital time on trauma patients outcome: a systematic review. Injury 2015;46:602-9.

12. O'Gara PT, Kushner FG, Ascheim DD, et al. 2013 ACCF/AHA guideline for the management of ST-elevation myocardial infarction: a report of the American College of cardiology Foundation/American heart association Task force on practice guidelines. Circulation 2013;127:e362-425.

13. Jauch EC, Saver JL, Adams HP, et al. Guidelines for the early management of patients with acute ischemic stroke: a guideline for healthcare professionals from the American heart Association/ American stroke association. Stroke 2013;44:870-947.

14. World Health Organization. Guidelines for trauma quality improvement programmes. Geneva, 2009. Available: whqlibdoc.who. int/publications/2009/9789241597746 eng.pdf

15. Lerner EB, Moscati RM. The Golden Hour: Scientific Fact or Medical "Urban Legend"? Acad Emergency Med 2001;8:758-60.

16. Osterwalder JJ. Can the "golden hour of shock" safely be extended in blunt polytrauma patients? Prospective cohort study at a level I hospital in eastern Switzerland. Prehosp Disaster Med 2002;17:75-80.

17. U.S. Census Bureau. Urban and rural classification. Available: https:// www.census.gov/geo/reference/urban-rural.html [Accessed 3 May 2016].

18. Sørensen PL. Lægehelikopterne ER på vej. Ugeskr Laeger 2004;166/40:3528-30: https://ugeskriftet.dk/nyhed/ laegehelikopterne-er-paa-vej.

19. Brøcker A, Rasmussen SR, Brandhøj MW. Akutlægehelikopter I Jylland. Evaluering AF forsøg Med akutlægehelikopter I region Midjylland OG region Nordjylland. Copenhagen Dansk Sundhedsinstitut; 2012. https://www.kora.dk/udgivelser/udgivelse/ i3944/Akutlaegehelikopter-i-Jylland

20. Regionernes akutlægehelikopter. Effektiv helikopterdækning af hele landet med 4 beredskaber - analyse og faglige anbefalinger. Danske Regioner, 2018. Available: https://www.regioner.dk/media/8646/ analyse_effektive-helikopterdaekning.pdf

21. Region Nordjylland. Ambulanceberedskab I region Nordjylland. Available: http://www.rn.dk/Om-Region-Nordjylland/DetPraehospitale-Beredskab/Kerneomraader/Ambulanceberedskab [Accessed 13 Oct 2015].

22. Aalborg Universitetshospital. Aalborg Traumecenter. Available: http:// www.aalborguh.rn.dk/Afsnit-og-ambulatorier/Akut-og-Traumecenter/ Afsnit/Aalborg-Traumecenter [Accessed 27 Dec 2015]. 
23. Dansk Selskab for Anæstesiologi og Intensiv Medicin \& Dansk Cardiologisk Selskab. Retningslinier for præhospital og interhospital transport af hjertepatienter, 2007. Available: https://www.nbv.cardio. $\mathrm{dk} /$ retningslinier-for-praehospital-og-interhospital-transport-afhjertepatienter [Accessed 3 Jun 2019].

24. Midt- Og Nordjylland. Fakta Om akutlægehelikopter, 2011. Available: https://www.rm.dk/siteassets/om-os/aktuelt/grafik/foto_bilag/ 110518_akutlagehelikopter/hems_akutlagehelikopter_fakta.pdf [Accessed 31 Oct 2018].

25. Pedersen CB. The Danish civil registration system. Scand J Public Health 2011;39(7 suppl):22-5.

26. Newgard CD, Meier EN, Bulger EM, et al. Revisiting the "Golden Hour": An Evaluation of Out-of-Hospital Time in Shock and Traumatic Brain Injury. Ann Emerg Med 2015;66:30-41.

27. Helweg-Larsen K. The Danish register of causes of death. Scand $J$ Public Health 2011;39(7 Suppl):26-9.

28. Gerds TA, RDocumentation. univariateTable function, 2018. Available: https://www.rdocumentation.org/packages/Publish/ versions/2018.04.17/topics/univariateTable [Accessed 5 Nov 2018].

29. Hernán M, Robins J. Causal Inference - Part 2. Boca Raton: Chapman \& Hall/CRC, 2018.

30. Daniel RM, Cousens SN, De Stavola BL, et al. Methods for dealing with time-dependent confounding. Stat Med 2013;32:1584-618.

31. Robins JM, Hernán MA. Estimation of the causal effects of timevarying exposures. In: Fitzmaurice G, Davidian M, Verbeke G, eds. Advances in longitudinal data analysis, 2008.

32. Harrell FE. Regression modeling strategies: with applications to linear models, logistic regression, and survival analysis. New York Springer; 2001.

33. Naimi Al, Cole SR, Kennedy EH. An introduction to G methods. Int J Epidemiol 2017;46:756-62.
34. R Core Team. R: a language and environment for statistical computing. Vienna, Austria R Foundation for Statistical Computing; 2012. www.r-project.org

35. Newgard CD, Schmicker RH, Hedges JR, et al. Emergency medical services intervals and survival in trauma: assessment of the "golden hour" in a North American prospective cohort. Ann Emerg Med 2010;55:235-46.

36. Spaite DW, Stiell IG, Bobrow BJ, et al. Effect of transport interval on out-of-hospital cardiac arrest survival in the OPALS study: implications for triaging patients to specialized cardiac arrest centers. Ann Emerg Med 2009;54:248-55.

37. Wei L, Lang CC, Sullivan FM, et al. Impact on mortality following first acute myocardial infarction of distance between home and hospital: cohort study. Heart 2008;94:1141-6.

38. Wang HE, Min A, Hostler D, et al. Differential effects of out-ofhospital interventions on short- and long-term survival after cardiopulmonary arrest. Resuscitation 2005;67:69-74.

39. Blackwell TH, Kline JA, Willis JJ, et al. Lack of association between prehospital response times and patient outcomes. Prehosp Emerg Care 2009;13:444-50.

40. Blanchard IE, Doig CJ, Hagel BE, et al. Emergency medical services response time and mortality in an urban setting. Prehosp Emerg Care 2012:16:142-51.

41. Blackwell TH, Kaufman JS. Response time effectiveness: comparison of response time and survival in an urban emergency medical services system. Acad Emerg Med 2002;9:288-95.

42. Andersen HR, Nielsen TT, Rasmussen $\mathrm{K}$, et al. A comparison of coronary angioplasty with fibrinolytic therapy in acute myocardial infarction. N Engl J Med 2003;349:733-42.

43. Bøtker MT, Stengaard C, Andersen MS, et al. Dyspnea, a highrisk symptom in patients suspected of myocardial infarction in the ambulance? a population-based follow-up study. Scand J Trauma Resusc Emerg Med 2016;24:15. 